\title{
CARACTERIZACIÓN LIMNOLÓGICA DE LA LAGUNA SALADA DE CHIPRANA (ZARAGOZA, ESPAÑA) Y SUS COMUNIDADES DE BACTERIAS FOTOTRÓFICAS
}

\author{
M. ${ }^{a}$ C. Guerrero, J. Balsa, M. Pascual, B. Martínez y C. Montes \\ Departamento Interuniversitario de Ecología, Facultad de Ciencias, Universidad Autónoma de Madrid. \\ 28049 Madrid, España.
}

Key words: Hypersaline lake, Spanish saline lake, water chemistry, phototrophic sulfur bacteria, microbial mats.

\author{
ABSTRACT \\ LIMNOLOGICAL CHARACTERIZATION OF THE SALADA DE CHIPRANA LAKE \\ (ZARAGOZA, SPAIN) AND ITS PHOTOTROPHIC BACTERIA COMMUNITIES
}

Salada de Chiprana lake, located at the Northeast of Spain, in the Ebro river basin, is the only permanent and deep water hypersaline ecosystem in Western Europe. With a total surface of about $0,31 \mathrm{~km}^{2}$, presents several basins with crenogenic seasonally stratification and its ionic composition is predominantly sulphate-magnesium. During 1989, its salinity range varied from 53 to $73 \%$. In the deep water (maximum depth 5,6 m), of higher salinity than the rest of the water column, oxygen depletion and hydrogen sulphide occur, together with the presence of light. Under these conditions, green anoxygenic phototrophic bacteria develop. On the other hand, laminated communities (microbial mats) can be found overlaying areas of the sediments of moderate slope, not deeper than $1 \mathrm{~m}$. The composition of the dominant species and the structure of both planctonic and benthic communities of phototrophic bacteria are described.

\section{INTRODUCCIÓN}

Los lagos salinos del mundo constituyen hoy día un importante tema de estudio por la multiplicidad de valores ambientales, sociales, económicos y científicos que encierran (HAMMER, 1986, WlLLIAMS, 1986). El estado actual de conocimiento sobre la microbiología y geoquímica de los sistemas hipersalinos ha sido recientemente publicado por JAVOR (1989).

Estos ecosistemas, si bien en muchos países adoptan un carácter marginal, en el caso de España constituyen una regularidad en el paisaje de sus regiones semiáridas, convirtiéndose en un patrimonio único para los países de Europa Occidental.

Limnetica, 7: 83-96 (1991)

(C) Asociación Española de Limnología, Madrid. Spain
De una forma general, las lagunas salinas españolas (valores mínimos de salinidad superiores a $10 \%$; Baltanás et al. 1990) son temporales (3 a 10 meses de inundación), poco profundas (5-70 $\mathrm{cm})$, con rangos de salinidad comprendidos entre $10-430 \%$, una composición iónica mayoritariamente mixta y clorurado sódica, y están sometidas a un elevado grado de fluctuación ambiental anual e interanual (Montes \& Martino, 1987).

En este contexto, la laguna Salada de Chiprana destaca por sus características ambientales únicas; se trata de una laguna de aguas permanentes hipersalinas de composición dominante sulfatado magnésica, que presenta muy pocas fluctuaciones de nivel a lo largo de todo el ciclo anual e interanual y con varias cubetas donde la profundidad supera los $5 \mathrm{~m}$. Las cubetas de mayor profundidad presentan además una estratificación estacional con una capa inferior más salina que el resto de 
la columna de agua, de carácter anóxico y rico en sulfuro de hidrógeno. El conjunto de todas estas características hace de la laguna un ambiente idóneo para un mundo bacteriano singular, el de las bacterias fototróficas. Éstas se encuentran tanto en la capa anóxica, formando un «bloom» prácticamente permanente, como tapizando los sedimentos en zonas de escasa pendiente dando lugar a las comunidades conocidas como tapetes microbianos.

En España se han llevado a cabo numerosos estudios en relación con las comunidades de procariotas fototróficas en lagunas litorales: Estany de Cullera (Valencia), La Massona (Gerona), Remolar (Barcelona) (Guerrero et al., 1987) y salinas costeras (Santa Pola, Alicante) (ThomAs, 1984). Sin embargo, no hay apenas referencias en lo que se refiere a los ambientes salinos del interior.

El objetivo de este trabajo preliminar es presentar los datos de las características limnológicas generales y comunidades de bacterias fototróficas de la Salada de Chiprana, dentro del marco general de los estudios de las lagunas salinas españolas que se lleva a cabo en el Dpto. de Ecología de la U.A.M., de cara a la caracterización y evaluación de los valores científicos que justifican su conservación a ultranza.

\section{MATERIAL Y MÉTODOS}

\section{Descripción del área de estudio}

La Laguna Salada de Chiprana se localiza en la zona centro-meridional de la Depresión del Ebro en la Comarca del Bajo Aragón, dentro del término municipal de Chiprana (Zaragoza) a unos 5 $\mathrm{km}$ de la localidad del mismo nombre. Situada sobre la cota de los $150 \mathrm{~m}$, es la laguna más baja de toda la Depresión del Ebro, a tan sólo $1 \mathrm{~km}$ del Arroyo del Regallo y $3,5 \mathrm{~km}$ del río Ebro que discurre a $130 \mathrm{~m}$ sobre el nivel del mar, marcando el nivel de base de la zona (fig. 1).

El clima es semiárido, al igual que en el resto del sector central de la Depresión del Ebro, con una media anual de precipitaciones del orden de $330 \mathrm{~mm}$ con máximos en primavera y otoño (fig. 1). La temperatura media es de $16^{\circ} \mathrm{C}$. Esto supone en la zona un déficit hídrico muy marcado que se ve intensificado por el fuerte viento de componente NW (cierzo), frío y seco. Este carácter de aridez se traduce en una inoperancia erosiva de la red fluvial que junto con la marcada horizontalidad del paisaje permite la existencia de zonas sin desagüe hacia los ejes exorreicos principales. Éste es el caso de la llanura interfluvial delimitada por los ríos Guadalope y Marín que mantiene una serie de focos endorreicos con numerosas depresiones y bastantes lagunas (núcleo endorreico del Bajo Aragón). Los más importantes son el foco de Alcaniz-Calanda y el de ChipranaCaspe donde se sitúa la laguna Salada (DANTín, 1942a, b; IBÁÑEZ, 1975).

Desde el punto de vista estratigráfico, la Salada de Chiprana se asienta sobre materiales detríticos de características lito-morfológicas muy peculiares con intercalaciones de calizas y yesos (Formación Caspe; Quirantes, 1978). Esta formación detrítica, de una edad miocena inferior u oligocena superior, se caracteriza por presentar unas formas del relieve realmente singulares y extraordinarias por su magnitud, abundancia, estado de conservación y rareza dentro del contexto europeo e incluso mundial (RIBA et al., 1967). Se trata de antiguos cauces o paleocanales terciarios procedentes de una extensa red fluvial meandriforme excavada en materiales margosos rellenados de areniscas y que quedaron cubiertos y fosilizados por colmatación de la cuenca. Posteriormente, estos cordones de areniscas, al ser más resistentes a la erosión que los materiales circundantes (margas), son exhumados y aparecen a modo de murallas o calzadas que pueden seguirse a veces varios kilómetros (RIBA et al., 1967; Friend et al., 1986).

Esta red de canales, que ha formado relieves invertidos por efecto de la erosión diferencial, posee un papel muy importante en la génesis de numerosas depresiones y cubetas de algunas lagunas de la zona. La red de paleocanales, al ser de distintas épocas, se entrecruza a diferentes niveles produciendo depresiones en cuyo fondo se encuentran materiales impermeables margosos y arcillosos, y en sus bordes se sitúan los muros de areniscas. La mayoría de estas depresiones más o menos cerradas no mantienen agua, por una parte, por el intenso déficit hídrico de la zona y por otra, porque ésta puede escapar por fisuración o incluso drenarse por los propios paleocanales ya que son bastante permeables por su composición cal- 
coarenítica. Sólo aquellas cubetas en las que las aguas subterráneas juegan un papel importante por descargas de flujos o drenaje impedido (BERNÁLDEZ, 1987) pueden mantener una lámina de agua durante más o menos tiempo.

La génesis de la laguna Salada de Chiprana queda, en términos generales, explicada dentro de este marco físico. Constituye uno de los mejores ejemplos de relieve invertido de la zona al quedar enmarcada por una red de paleocanales que pe- netra en la laguna a modo de espigón, diferenciando varias cubetas. El carácter permanente y poco fluctuante de sus aguas, en una zona de un gran déficit hídrico y escasas precipitaciones, sólo puede explicarse por el efecto de flujos subterráneos relacionados con los materiales terciarios más permeables. Aún no se conoce nada sobre este sistema de flujos, que abastece hídricamente a la laguna. La permeabilidad y dirección de los paleocanales podrían tener una gran importancia

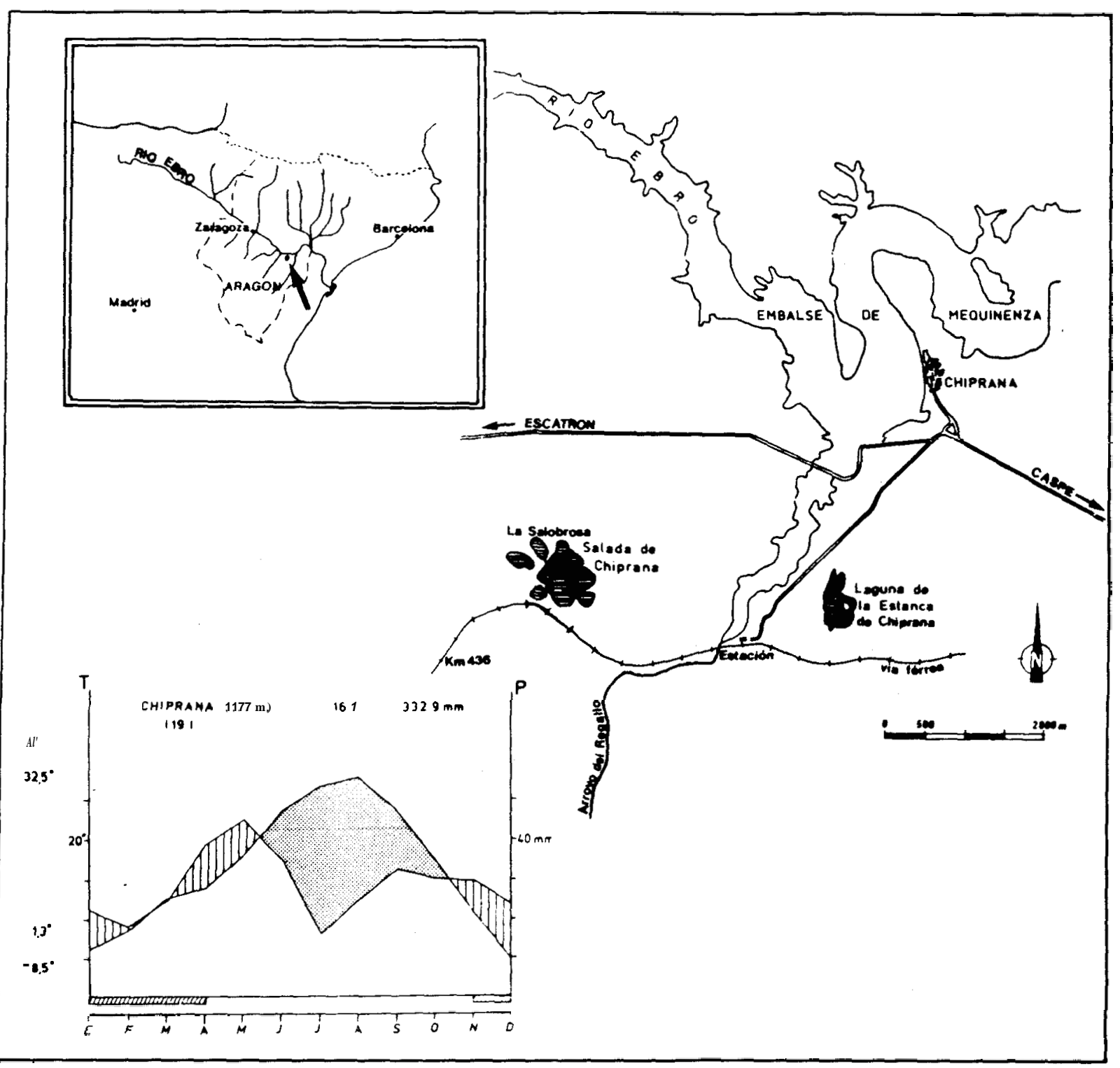

Figura 1.- Localización del área de estudio y climodiagrama de la zona Location and Walter-Lieth climate-diagram of the study area. 
Tabla 1. - Parámctros morfométricos más importantes de la La guna Salada de Chiprana para el ciclo hidrológico 1987/88 (expresiones según Hakanson, 1981). a = área total. $\mathrm{V}=$ volumen. $Z \max =$ profundidad máxima. $\mathrm{Zni}=$ profundidad media. $\mathrm{Zr}=$ profundidad relativa. $\mathrm{DI}=$ desarrollo de la linea de costa. $\mathrm{Dv}=$ desarrollo del volumen. $\delta \mathrm{m}=$ pendiente media. In = insularidad. $\mathrm{R}=$ desigualdad del fondo, $\mathrm{L}=$ perímetro. Lmnx = longitud máxima. Lmaxe = longitud máxima efectiva, $B \max =$ anchura máxima. $B \operatorname{maxc}=$ anchura máxima efectiva.

Morphometric parameters of Salada de Chiprana Lake during the hydrological cycle 1987188 (notation following Hakanson. 19811 .

\begin{tabular}{lll}
\hline $\mathrm{a}=31.5 \mathrm{ha}$ & $\mathrm{DI}=1.89$ & $\mathrm{~L}=3.749 .6 \mathrm{~m}$ \\
$\mathrm{~V}=71.7 \mathrm{hm}$ & $\mathrm{DV}=1.27$ & $\mathrm{Lmax}=702.4 \mathrm{~m}$ \\
$\mathrm{Zmax}=5.6 \mathrm{~m}$ & $\delta \mathrm{m}=3.4 \%$ & $\mathrm{~L} \operatorname{maxc}=792.4 \mathrm{~m}$ \\
$\mathrm{Zm}=2.3 \mathrm{~m}$ & $\mathrm{In}=1.3 \%$ & $B \max =69.3 \mathrm{~m}$ \\
$\mathrm{Zr}=0.86 \mathrm{~m}$ & $\mathrm{~K}=5.67$ & $B \max =523.5 \mathrm{~m}$ \\
\hline
\end{tabular}

para entender la hidrogeología de la zona. La elevada salinidad de sus aguas podría explicarse por flujos muy mineralizados procedentes del lavado de formaciones de yesos, material que también se observa en varias zonas junto a sus orillas donde se han excavado algunas zanjas. Las características sedimentológicas generales de la laguna han sido descritas por Puf-Yo (1978179) y MingarRo et al. (1981).

$A$ la laguna se le supone un origen relativamente reciente (cuaternario medio), ya que tiene cerrado su drenaje hacia el Ebro por una colina aluvial cuaternaria de 80 a $85 \mathrm{~m}$ de altitud (IBÁNEZ, 1973, 1975).

La Salada forma parte de todo un complejo de depresiones formadas por la red de paleocanales de la zona de Chiprana, la mayoría de los cuales no recogen agua. Sólo habría que destacar la laguna de la Estanca de Chiprana (13,24 ha) cerca de la Estación, de aguas profundas, permanentes y dulces ya que está transformada en embalse al recibir las aguas del río Guadalope por una acequia. Colindantes con la Salada existen otras dos lagunas, La Salobrosa $(2,8$ ha) y otra sin nombre (1,51 ha) completamente colmatada y cubierta por un denso carrizal. La Salobrosa, que en tiempos atrás debió de ser de aguas salinas, actualmente está endulzada al recibir los sobrantes de regadíos de la zona por una acequia (fig. 1).

El régimen hidrológico natural de la laguna Salada es cerrado pero se ve alterado por un aporte prácticamente continuo de agua dulce procedente de la Salobrosa a la que queda unida por un pequeño canal excavado en el terreno y cale provoca una lengua de agua dulce poco extensa que penetra en la laguna. También, de una forma intermitente, recibe desde marzo a octubre, por otros canales excavados alrededor de su cubeta, vertidos de agua dulce procedentes del sobrante de riego de la zona, llegando a producir, según los ciclos hidrológicos, cambios importantes de nivel y por tanto de la salinidad de sus aguas.

En la figura 2 se presenta el mapa batimétrico de la laguna realizado mediante transectos longitudinales por toda la laguna y empleando una sonda nivelada. En la tabla 1 se presentan los valores de los parámetros morfométricos más importantes. Posee una forma más o menos redondeada, con una superficie de 31,5 ha de las cuales 0,4 ha corresponden a paleocanales que penetran en ella, lo que supone un índice de insularidad del 1,3\%.

La profundidad está en función de la inundación anual e interanual llegando a los 5,6 m en algunas zonas de la cubeta central con una media de $2,3 \mathrm{~m}$. La pendiente es del $3 \%$, más pronunciada en la proximidad de los paleocanales y menor en las zonas de entrada del agua de escorrentia. Los fondos son bastante planos debido a la intensa capa de limos que los cubre, que llega a tener en algunas zonas un espesor superior a $1 \mathrm{~m}$.

La vegetación acuática de sus aguas y sus orillas posee un gran valor ambiental por la singularidad florística y ecológica de sus comunidades, además de su rareza dentro de un contexto europeo. Ha sido estudiada de una forma somera por algunos autores como Reyes ProsPer (1915), Braun Blanquet \& Bolós (1957), Margalef Mir (1981) e Izco et al. (1984). Por el carácter forzado del ambiente, producido por la elevada salinidad de sus aguas, sólo dos especies de macrófitos acuáticos sumergidos se desarrollan en sus fondos: Ruppia maritima L. var. maritima tapiza grandes zonas de las orillas más tendidas e iluminadas hasta la isolínea de aproximadamente $0,8 \mathrm{~m}$ de profundidad. A continuación se desarrolla una densa pradera del carófito Lamprothumium papulosum (Wallr.) J. Groves, que puede llegar a profundidades considerables $(3 \mathrm{~m})$ con una distancia internodal relacionada con la disponibilidad de la luz. En algunas pequeñas charcas temporales de 
alrededor de sus orillas se encuentra también Ruppia drepanensis Tineo.

La vegetación marginal es escasa y está formada básicamente por manchas de carrizos (Phragmites australis [Cav.] Trin.). En las playas de la laguna sc instalan saladares bien conservados constituidos por bandas más o menos anchas de vegetación halófila que se disponen según el gradiente de salinidad e inundacicín (Salicornia ramosissima J. Woods, Suaeda maritima (L.) Dumort., S. vera J.F. Gmelim, Limonium spp., Inula crithmoides
L., Aeluropus littoralis (Gonan) Parl., etc.). En las zonas menos encharcadas y con un cierto contenido en materia orgánica aparecen juncales de Juncus maritimus Lam., J. acutus L., Scirpus muritimus L. y $S$. holoschenus $L$. También hay que resaltar en la zona noroeste de la laguna un bosyuete de gran porte y relativamente bien conservado de Tamarix boveana y $T$. cutzuriensis Willd.

El zooplancton de sus aguas es también, por su carácter hipersalino, muy pobre en especies. Constituye la única cubeta natural interior espa-

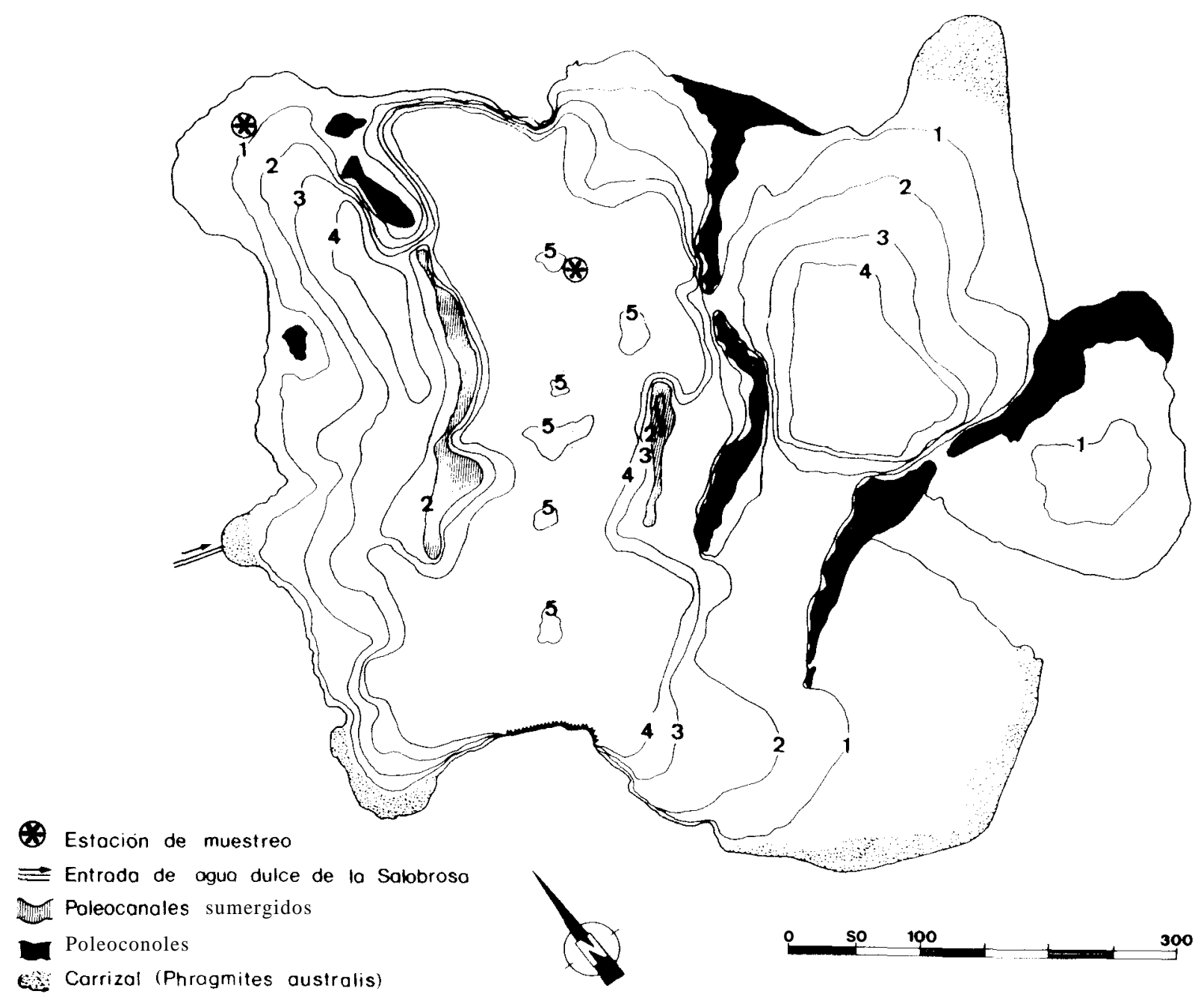

Figura 2.- Mapa batimétrico de la Salada de Chiprana (mayo 1988) mostrando las estaciones de muestreo de las coinunidades de bacterias fototróficas.

Bathymetric map of the Salada de Chiprana lakc (may 1988), showing sampling stations of phototrophic bacteria communitıes. 
ñola donde se puede encontrar una población muy abundante del Anostráceo Artemia salina (L.). Acompañando a esta especie se presentan los Copépodos Arctodiaptomus salinus (Daday) y Cletocamptus retrogressus Schmank, además de los Rotíferos Hexarthra fennica y Brachionus plicatilis (Martino, 1987). El endulzamiento que ha sufrido la laguna durante el ciclo estudiado ha cambiado su composición específica y en los dos últimos ciclos no se han encontrado individuos de Artemia salina.

El zoobentos está formado casi exclusivamente por Dípteros de la familia Ephydridae, cuyos adultos forman grandes masas a lo largo de sus orillas más tendidas. Sólo en la zona afectada por el agua dulce procedente de la Salobrosa viven algunos ejemplares de Gambusia affinis. La elevada salinidad de sus aguas no permite que se desarrolle en otras partes de la laguna ninguna especie de vertebrados a pesar de su carácter permanente (peces o anfibios).

$\mathrm{Su}$ comunidad de aves acuáticas no es tampoco muy rica en especies ni abundante en individuos (BALlarín, 1985) aunque cabe destacar la presencia de una pequeña población de tarro blanco ( $\mathrm{Ta}$ dorna tadorna).

El paisaje que rodea el complejo palustre está monopolizado por el cultivo cerealista de secano con cada vez mayor extensión de regadío, quedando muy pocas áreas con una vegetación natural esteparia.

\section{Muestreo}

Se realizó un muestreo mensual durante un ciclo hidrológico completo (enero a diciembre de 1989). Las muestras para la determinación de los parámetros fisicoquímicos de la laguna, así como para el estudio de las comunidades de bacterias fototróficas planctónicas, se tomaron a lo largo de un perfil vertical, en la cubeta de mayor profundidad situada frente a los paleocanales centrales (fig. 2).

La conductividad y temperatura se determinaron mediante un conductivímetro de campo con sonda de temperatura (INSTRAND-10) y el pH y potencial de óxido-reducción con un pHmetro portátil (Crison 506 con electrodo Metrohn de ORP).
Los iones mayoritarios, nutrientes, oxígeno y sulfuro de hidrógeno se determinaron según la metodología propuesta en el APHA (1985) con modificaciones (BERNUÉs et al., 1990).

La concentración de bacterioclorofila se determinó según Clayton (1966).

Para la determinación de las bacterias fotosintéticas anoxigénicas planctónicas se recogieron muestras, mediante un sistema de bombeo controlado, a distintas alturas del perfil por debajo de la quimioclina, que se trasladaron en frío y oscuridad al laboratorio para la observación en vivo, análisis espectroscópico (mediante espectofotómetro Hitachi U-2000) y aislamiento. Así mismo se fijaron muestras con formaldehído tamponado con borato ( $2 \%$ final) para su estudio por microscopía óptica y electrónica. La determinación del tipo de bacterioclorofila se realizó mediante espectros in vivo de una suspensión de células en fi-

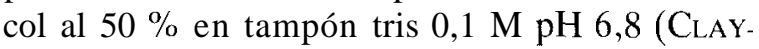
TON, 1966) y por extracción en acetona $90 \%$ (GLOE et al., 1975). El aislamiento se llevó a cabo por el método de cultivo en tubos de agar con el medio descrito por VAN GEMERDEN et al. (1985).

Los tapetes se muestrearon periódicamente en una zona de playa previamente delimitada (fig. 2), a una profundidad media de $55-60 \mathrm{~cm}$ donde se realizaban las mismas determinaciones fisicoquímicas citadas anteriormente. Asimismo se tomaron muestras en un transecto horizontal desde la estación de muestreo fija hasta la orilla. Se recogieron secciones verticales mediante un tubo hueco de PVC transparente de $45 \mathrm{~mm}$ de diámetro, que fueron analizadas al microscopio óptico (Olympus BH-2) para determinar su composición y la frecuencia relativa de formas morfológicas.

Las determinaciones espectroscópicas de clorofila y bacterioclorofilas se realizaron según STAL $\boldsymbol{e t}$ al. (1984). Parte de las muestras se fijaron con formal al $4 \%$ para la realización de espectros y observación al microscopio electrónico de barrido (PSEM 500 de Philips).

La clasificación de los tipos observados se ha realizado según la denominación genérica provisional de RipKa et al. (1979). Por razones de comparación con otros trabajos se ha seguido, en algunos casos, la clasificación de GEITLER (1932). 


\section{RESULTADOS}

\section{Características físico-químicas de las aguas}

En la tabla 2 se presentan los valores medios, cociente de variación y máximos y mínimos de los principales parámetros fisico-químicos de la Salada de Chiprana a lo largo del período de muestreo, en un punto de la superficie $(0 \mathrm{~m})$ y del fondo $(4,5 \mathrm{~m})$.

En la figura 3 se muestra la distribución vertical de algunos parámetros fisico-químicos y biológicos en dos períodos del ciclo anual estudiado.

La lámina de agua no experimenta fluctuaciones notables de profundidad a lo largo del ciclo anual, habiéndose observado una variación máxima de $60 \mathrm{~cm}$ entre los períodos extremos.

La salinidad, así como el resto de sus componentes mayoritarios, presentan pequeñas oscilaciones (bajos valores de cv, tabla 2) a lo largo de su ciclo anual, aunque sí posee diferencias significativas interanuales según el balance precipitación-temperatura y especialmente dependiendo del aporte de agua dulce que reciba de los regadíos de la zona. De esta forma, para el ciclo estudiado, las oscilaciones fueron de $29,5 \%$ en super- ficie después de unas lluvias intensas (diciembre 1989) hasta $73,2 \%$ en el fondo (abril 1989). Durante otras prospecciones realizadas en la laguna en ciclos anteriores por nosotros y otros autores, se han registrado valores superiores en superficies: $74,1 \%$ (marzo 1978, Mingarro et al. 1981), $83,9 \%$ (mayo 1987) y $75,9 \%$ (mayo 1988). La media para el ciclo estudiado fue de 59,2\%. En casi todas las muestras tomadas los valores entran dentro del rango de las aguas u-hipersalinas (PoR, 1980).

La salinidad muestra un perfil vertical caracterizado por presentar una quimioclina (fig. 3) que se sitúa a lo largo del ciclo anual entre los 1,75 y $4,50 \mathrm{~m}$ de profundidad, delimitando una capa inferior más salina que crea unas condiciones de estratificación prácticamente estables de tipo crenogénico (Wetzel, 1983).

La transparencia, medida por el disco de Secchi, oscila desde un máximo en mayo, a 2,4 $\mathrm{m}$ de profundidad, hasta un mínimo en octubre, a 0,7 $\mathrm{m}$, coincidiendo con un período de mezcla de las aguas por el fuerte viento.

La temperatura presenta pocas variaciones a lo largo del perfil vertical en todos los muestreos, con mínimos y máximos entre $7,1^{\circ} \mathrm{C}$ a $24^{\circ} \mathrm{C}$ en

Tabla 2.- Valores medios (x), cociente de variación (cv) y máximos y mínimos de los principales parámetros físicos y químicos, en superficie y quimiolimnion, de la Laguna Salada de Chiprana a lo largo del período de estudio (1989). $\mathrm{n}=$ tamaño de la muestra. Mean (x), coefficient of variation (cv) and maximum and minimum values of the major physical and chemical parameters, at the surface and chemolimnion, of the Salada de Chiprana lake, during 1989. $\mathrm{n}=$ sample size.

\begin{tabular}{|c|c|c|c|c|c|c|c|c|}
\hline \multirow[b]{3}{*}{$T\left({ }^{\circ} \mathrm{C}\right)$} & \multicolumn{4}{|c|}{ Superfície $n=10$} & \multicolumn{4}{|c|}{ Fondo $n=10$} \\
\hline & \multirow{2}{*}{$\frac{x}{17.0}$} & \multirow{2}{*}{$\frac{c v(\%)}{32,5}$} & \multicolumn{2}{|c|}{$\min -\max$} & \multirow{2}{*}{$\frac{x}{16,8}$} & \multirow{2}{*}{$\frac{c v(\%)}{19,6}$} & \multicolumn{2}{|c|}{ mín-mâx } \\
\hline & & & 7,1 & 24,0 & & & 11,8 & 23.0 \\
\hline $\mathrm{C}(\mathrm{mS} / \mathrm{cm})$ & 40,4 & 14,3 & 27.2 & 51,1 & 47.0 & 6,4 & 42,7 & 51.8 \\
\hline Sal $(\%)$ & 54,3 & 17.5 & 29.6 & 64,0 & 64,9 & 10,8 & 53,3 & 73,2 \\
\hline $\mathrm{pH}$ & 8,3 & 1,2 & 8,2 & 8,5 & 7,6 & 7,3 & 6,8 & 8,4 \\
\hline Eh $(m V)$ & 117,2 & 45.7 & 15.0 & 193.0 & $-355,6$ & 27,3 & $-480,0$ & $-37,0$ \\
\hline $\operatorname{AT}(\mathrm{meq} / \mathrm{l})$ & 9,8 & 8,9 & 8,5 & 11,1 & 21,2 & 48.2 & 11.8 & 42,5 \\
\hline $\mathrm{C}_{3}^{2-}(\mathrm{meq} / 1)$ & 1.6 & 44,0 & 0.7 & 2,8 & 0,6 & 153,8 & 0,0 & 3,1 \\
\hline $\mathrm{SO}_{4}^{2-}(\mathrm{meq} / 1)$ & 616,5 & 21,2 & 323,4 & 773,0 & 728.4 & 14,2 & 575,6 & 877,0 \\
\hline $\mathrm{Cl}(\mathrm{meq} / \mathrm{l})$ & 257.0 & 14,5 & 154.9 & 277,6 & 320.4 & 5,1 & 287,8 & 308,0 \\
\hline $\mathrm{Ca}^{2+}(\mathrm{meq} / 1)$ & 29,2 & 15,9 & 17,0 & 34,8 & 28,1 & 19,3 & 14.0 & 32,0 \\
\hline $\mathrm{Mg}^{2+}($ meq/1) & 549,4 & 15,6 & 311,0 & 602,0 & 678.8 & 6,1 & 626,0 & 715.2 \\
\hline $\mathrm{Na}^{+}$(meq/l) & 333,3 & 21,3 & 159,2 & 413,7 & 420,5 & 12,8 & 298.4 & 474,1 \\
\hline $\mathrm{K}^{+}(\mathrm{meq} / \mathrm{l})$ & 3,5 & 16,9 & 2,4 & 4,3 & 4.1 & 18,1 & 2,6 & 5,0 \\
\hline $\mathrm{NH}_{\underline{4}}^{+}(\mathrm{mg} / \mathrm{l})$ & 0,4 & 59,3 & 0,01 & 0,8 & 24,8 & 91,4 & 9,0 & 66,4 \\
\hline $\mathrm{NO}_{3}^{-}(\mathrm{mg} / \mathrm{l})$ & 10,7 & 82,1 & 3.9 & 32,7 & 0.0 & - & - & - \\
\hline $\mathrm{PO}_{4}^{2--}(\mathrm{mg} / 1)$ & 0,1 & 139,5 & 0,0 & 0,2 & 0.4 & 100,0 & 0,0 & 0,9 \\
\hline $\mathrm{O}_{2}(\mathrm{mg} / \mathrm{l})$ & 4,4 & 35.5 & 2.4 & 7,1 & 0,0 & $\overline{-}$ & - & - \\
\hline $\mathrm{SH}_{2}(\mathrm{mg} / \mathrm{l})$ & 0.0 & - & & - & 93.2 & 76.4 & 0.0 & 210.6 \\
\hline
\end{tabular}


superficie, y $11,8^{\circ} \mathrm{C}$ a $21,5^{\circ} \mathrm{C}$ en profundidad. Durante los meses de verano la temperatura presenta iin gradiente vertical suave a lo largo del perfil que se invierte en los meses fríos sin que nunca se llegue a presentar una estratificación térmica clara (fig. 3).

La composición iónica de sus aguas es predominantemente de carácter sulfatado-magnésico con concentraciones considerables de $\mathrm{Cl}$ y $\mathrm{Na}^{+}$, reflejando la calidad de las formaciones evaporíticas. que son lixiviadas por las aguas subterráneas y de lluvia.

La serie iónica de Eugster \& Hardie (1978) para la práctica totalidad de las muestras en el ciclo estudiado, así como de otras de ciclos anteriores (Pueyo, 1978179; Mingarro et al., 1981), es del tipo $\mathrm{SO}_{4}-\mathrm{Cl}-\mathrm{Mg}-\mathrm{Na}$. Junto con la laguna Salada Sulfúrica (Zaragoza) constituye la cubeta con las aguas más ricas en sulfato y magnesio de toda la depresión del Ebro.

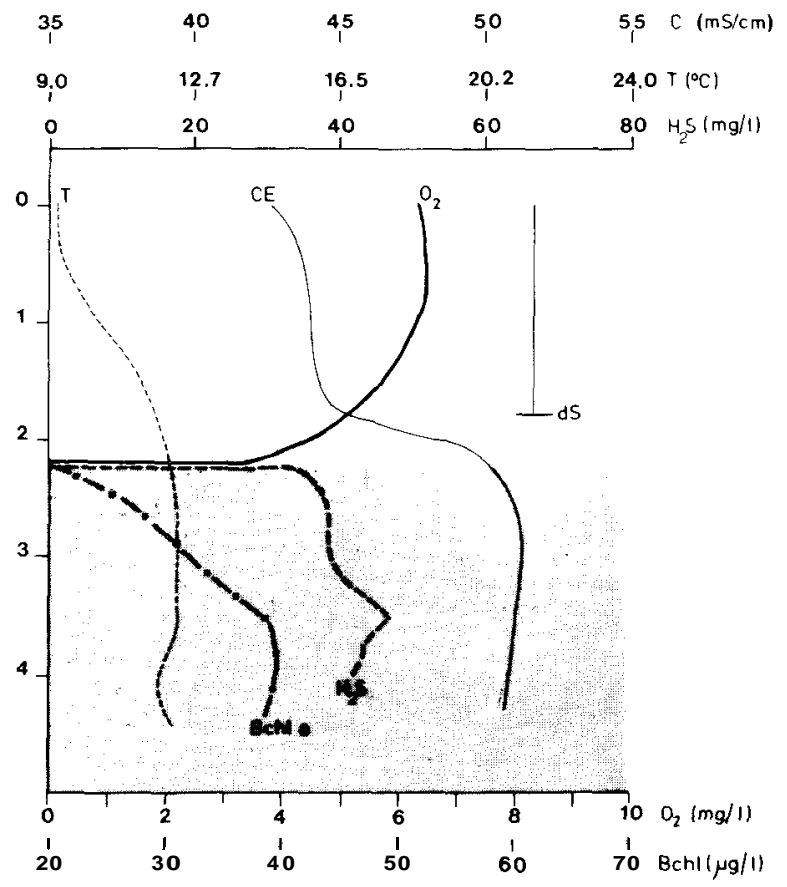

A
Las concentraciones de oxígeno y sulfuro de hidrógeno presentan una distribución vertical complementaria, en relación con la presencia de una estratificación casi permanente. Los valores de oxígeno muestran un gradiente decreciente a lo largo del perfil hasta llegar a la quimioclina; por debajo de ésta, las aguas permanecen anóxicas durante todo el ciclo (fig. 3), exceptuando el mes de octubre en que, por efecto de los fuertes vientos, se homogeneiza el perfil, detectándose en el fondo 1,3 mgll de oxígeno.

El aislamiento de la atmósfera de la capa profunda y la ausencia de oxígeno, permiten la acumulación en la misma de sulfuro de hidrógeno en altas concentraciones, procedente tanto de la descomposición de la materia orgánica como de la actividad sulfato-reductora. En los meses de verano las concentraciones de sulfuro de hidrógeno en el fondo de la laguna llegan a alcanzar valores de $210,6 \mathrm{mg} / 1$.

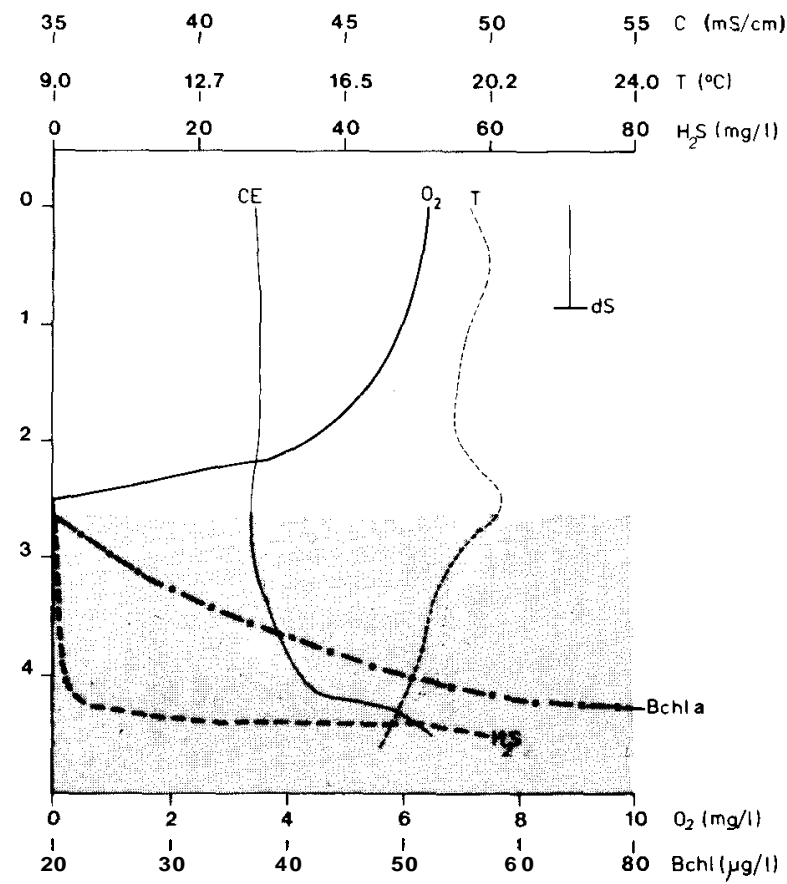

$\mathbf{B}$

Figura 3.- Distribución vertical de algunos parametros fisicoquímicos y biológicos de la Salada de Chiprana en dos períodos extremos: invierno (A, enero 1989), y verano (B, junio 1989). La zona con trama oscura muestra la distribución de las bacterias fotosintéticas.

Vertical profiles of some physicochemical and biological parameters of the Salada de Chiprana lake in two different periods: winter (A, January 1989), summer (B, June 1989). The shaded area shows the distribution of photosynthetic bacteria. 
El potencial redox presenta durante todo el ciclo, exceptuando el mes de octubre, un gradiente descendiente a lo largo del perfil, alcanzándose siempre en las aguas más profundas valores de Eh $<0 \mathrm{mV}$. El rango oscila entre un máximo de +193 mV en superficie y un mínimo de $-436 \mathrm{mV}$ en profundidad.

\section{Poblaciones de bacterias fototróficas planctónicas}

En las cubetas de mayor profundidad, la existencia de una estratificación prácticamente permanente asociada a la presencia de sulfuro de hidrógeno, carencia de oxígeno y suficiente intensidad lumínica, determina el crecimiento, por debajo de la termoclina, de bacterias fotosintéticas verdes del azufre.

El espesor de la capa de agua en la que se encuentran las bacterias verdes varía a lo largo del ciclo anual, paralelamente a la variación de grosor de la capa anóxica, como se muestra en la figura 3, donde la zona de trama punteada oscura muestra la distribución de bacterias fotosintéticas. El máximo espesor se consigue en invierno, donde llega a alcanzar, en el muestreo de enero de 1989, los 3 m, y el mínimo en los meses de verano, con sólo $50 \mathrm{~cm}$ a finales de julio del mismo año.

Los espectros de absorción realizados con muestras de agua tomadas a distintas profundidades, dentro de la capa anóxica, presentan siempre los mismos máximos de absorción, y asimismo se mantienen constantes a lo largo del ciclo anual, indicando la presencia de una población dominante única.

En la figura 4 se muestra el espectro de absorción in vivo $e$ in vitro de las bacterias fotosintéticas, con los máximos correspondientes a bacterioclorofila d y clorobacteno (GLOE, 1975), propios de las bacterias fototróficas pertenecientes a la familia Chlorobiaceae. El posterior aislamiento y análisis de las características morfológicas y de cultivo, indican que la especie dominante durante todo el ciclo anual correspondería a Chlorobium vibrioforme, aunque llama la atención su capacidad de crecimiento al $\mathrm{pH}$ tan elevado de la laguna, que sobrepasa habitualmente en más de una unidad los rangos descritos para el crecimiento de todas las clorobiáceas en el Manual de Bergey (STAley, 1989). No obstante, también se han de- tectado colonias de bacterias fototróficas rojas, pertenecientes al género Chromutium y marrones, correspondientes a miembros de la familia Chlorobiuceae que presentan este color en cultivo puro, aunque, por su bajo número, su contribución a la biomasa total es mínimo.

\section{Tapetes microbianos}

La laguna Salada de Chiprana presenta un extenso desarrollo de comunidades bénticas multila-
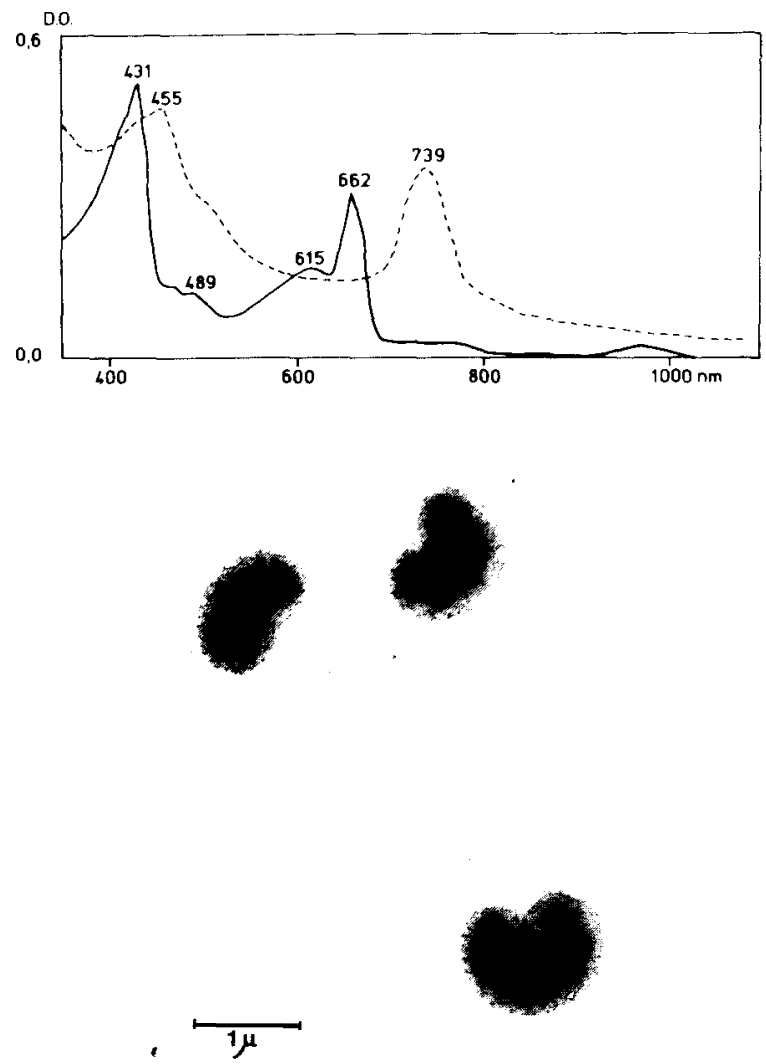

Figura 4.- Espectro de absorción in vivo (- - - -) y del extracto acetónico (-----) de las bacterias verdes del azufre aisladas de la capa anóxica de la Salada de Chiprana (A). Micrografía electrónica (tinción negativa, acetato de uranilo $2 \%$ ) de las bacterias aisladas en cultivo puro (B).

Absortion spectra in vivo (- . -) and of the acetonic extract (----) of the green sulfur bacteria isolated from the anoxic layer of the Salada de Chiprana (A). Electronic micrograph (negative stain, uranyl acetate $2 \%$ ) of the bacteria isolated in pure culture (B). 
minadas conocidas como tapetes microbianos. Los sedimentos en áreas de pendiente moderada y hasta una profundidad que oscila entre 1-13 m están cubiertos por este tipo de comunidades, en zonas de vegetación acuática dispersa o ausente. En el área de muestreo, situada en la zona de playa de la laguna (fig. 2), en el extremo noroeste de la misma, forman un tapiz relativamente continuo, con una distribución más irregular en los primeros $10 \mathrm{~m}$ próximos a la orilla. En esta zona, la más somera, los tapetes ocupan áreas dispersas alternándose con el macrófito acuático sumergido $R u p$ piu maritima L. var. maritima.

En la zona de orilla, la más sujeta a fluctuaciones de inundación desecación, se encuentra el tapiz más joven, poco estructurado y poco compacto, que corresponde a las etapas iniciales de su formación. A partir de los 15-20 m de la orilla y unos $40 \mathrm{~cm}$ de profundidad, el tapete adquiere consistencia notable, con un grosor total de sus capas constituyentes vivas que oscila de 5 a $10 \mathrm{~mm}$ dependiendo del crecimiento bacteriano y la captura de sedimento.

La estación de muestreo estaba situada a una profundidad media de $60 \mathrm{~cm}$ bajo condiciones de inundación permanente, lo que permite el desarrollo estable del tapiz microbiano maduro durante todo el ciclo anual. La fluctuación máxima de nivel del agua en esta zona fue de $28 \mathrm{~cm}$ a lo largo de 1989, con una variación de temperatura entre $5^{\circ}$ y $32^{\circ} \mathrm{C}$ y un rango de salinidad de $30,76 \%$ (diciembre, tras fuertes precipitaciones) a $64,11 \%$.

En cuanto a la estructura y composición de los tapetes (fig. 5), las comunidades maduras presentan una capa superficial de color pardo verdoso, constituida básicamente por microalgas eucarióticas, fundamentalmente diatomeas pennadas (Nitzchia sp., Navicula sp.). Asimismo, y en menor proporción, es común la presencia de clorofíceas cocoidales y cianobacterias unicelulares: Gloeocapsa sp. (Chroococcus turgidus según GEITLER), Synechococcus sp. Durante la mayor parte del año, la superficie presenta característicamente una estructura en forma de conos (pinnacle mat) producidos por el crecimiento vertical de cianobacterias filamentosas. Por debajo de la capa superficial aparece una capa subyacente de color verde, con un grosor variable de 3-7 mm, constituida por una sucesión de láminas organo-detríti- cas que tienen su origen en la yuxtaposición de fenómenos de sedimentación y crecimiento bacteriano. Esta capa está básicamente formada por una cianobacteria LPP B que ha sido clasificada según GeITLER como Microcoleus chthonoplastes. Junto a ésta aparecen otras formas filamentosas cuya contribución cuantitativa varía en las diferentes épocas del año, entre las que destacan Oscillatoria sp. (Oscillatoria cf. nigroviridis según GEITLER), Spirulina sp., Pseudoanabaena sp., 3 cepas aisladas de LPP B (Phormidium spp. según GEITLER) y flexibacterias. Las formas unicelulares son también frecuentes, apareciendo aisladas o en colonias, fundamentalmente Synechococcus sp. y Gloeocupsa sp. La abundancia relativa de las distintas formas citadas varía a lo largo del ciclo anual. Ello condiciona la mayor o menor cohesión del tapete, ya que ésta viene dada por el entramado de los tricomas, por la captura de sedimento y por la adhesión entre las cápsulas envolventes tanto de las formas filamentosas como de las unicelulares que las presentan.

En los meses de verano se observa, por debajo de la capa verde, una fina capa roja, del orden de $1 \mathrm{~mm}$ de grosor, constituida por bacterias fotosintéticas rojas del azufre, predominantemente de los géneros Chromatium y Thiospirillum. El resto del ano estos organismos fototróficos están presentes pero de forma dispersa en el tapete. Otras formas bacterianas como Beggiatoa sp., Spirillum sp. y bacterias heterotróficas diversas son también muy abundantes por la gran cantidad de materia orgánica presente en el medio.

Por debajo de las capas mencionadas se encuentra el sedimento anóxico de color negro por el sulfuro de hierro producido como consecuencia de la actividad de las bacterias sulfato-reductoras. Este sedimento presenta una notable consistencia en los primeros milímetros al encontrarse entramado por restos muertos de formas filamentosas.

Esta composición general es común a todos los tapetes de la laguna, de los cuales se han recogido ocasionalmente muestras puntuales para su observación.

Además se ha observado la presencia de distintos organismos posibles consumidores del tapete, tales como nemátodos, ciliados y restos de invertebrados acuáticos, fundamentalmente rotíferos, cuyo papel en las cadenas tróficas está aún por determinar. 
En cuanto a los tapetes jóvenes que se forman en las zonas próximas a la orilla y sometidos por tanto a condiciones más extremas (fluctuación de inundación-desecación, intensidad lumínica, etc.) su estructura es más simple consistiendo, fundamentalmente, en láminas muy delgadas de color pardo amarillento constituidas básicamente por diatomeas pennadas y cianobacterias unicelulares con una finísima capa subyacente constituida por paquetes de Microcoleus chthonoplastes, Pseudoanabaena sp. y flexibacterias. La mayor abundancia de diatomeas y cianobacterias unicelulares provistas de pigmentos pardos en estos tapetes de orilla estaría relacionada con un papel de protección contra la fotooxidación y la elevada intensidad lumínica.

\section{DISCUSIÓN}

La laguna Salada de Chiprana es uno de los humedales más singulares del endorreismo aragonés e ibérico por la rareza de sus características am-

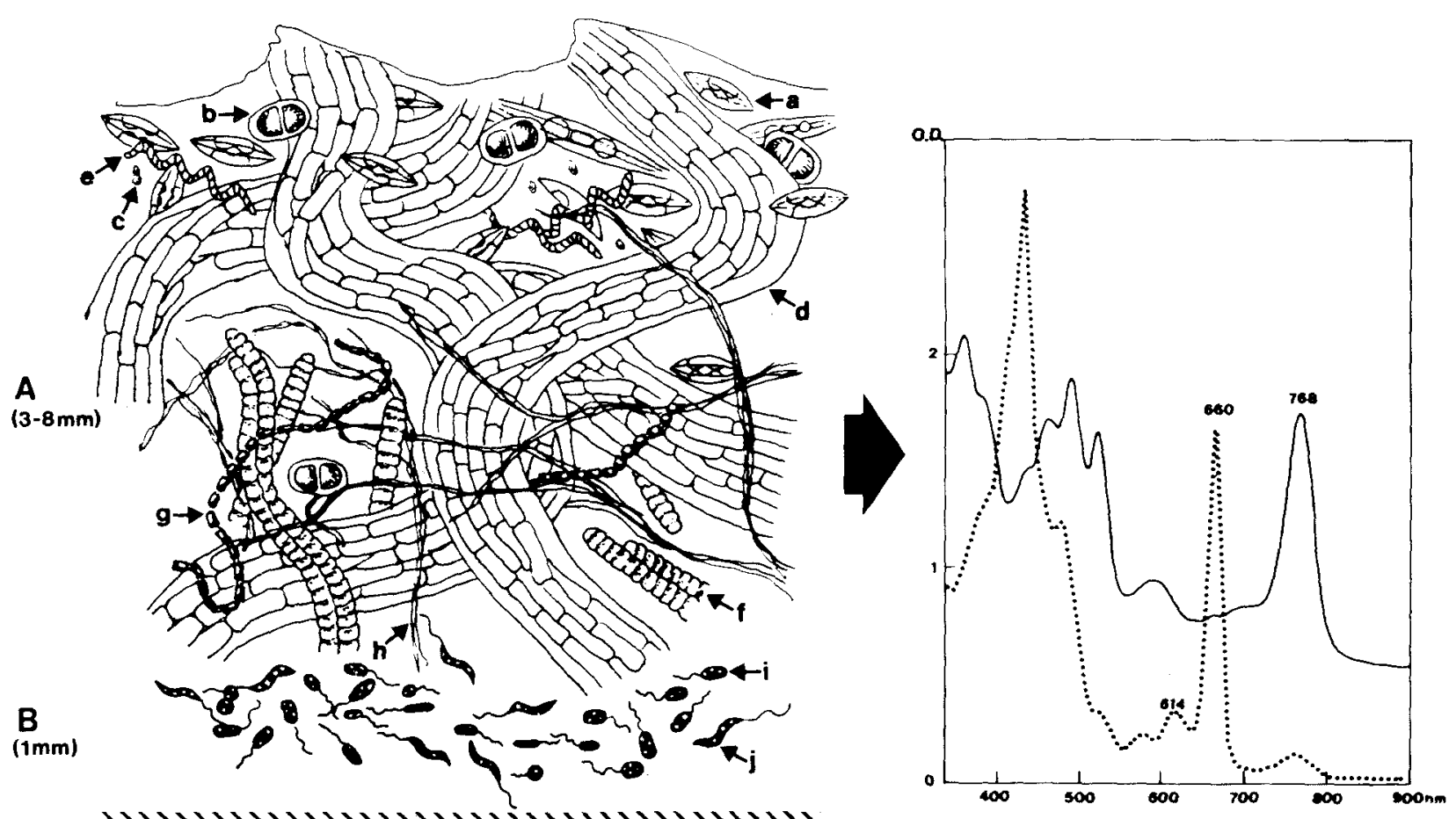

C

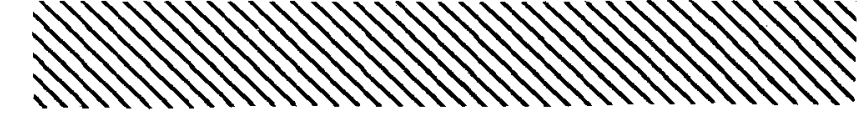

Figura 5.- Esquema del corte transversal de un tapete de verano mostrando las distintas capas básicas que lo componen y los espectros de absorción en hexano de las capas verde (.....) y roja (----) del mismo. Los picos a 660 y 614 nm son debidos a la clorofila a y el pico a $768 \mathrm{~nm}$ a la bacterioclorofila a.

Las letras en el dibujo corresponden a: A, diatomeas y cianobacterias; B, bacterias fotosintéticas rojas del azufre; C, bacterias sulfato-reductoras; a, diatomeas; b, Gloeocapsa sp.; c, Synechococcus sp.; d, Microcoleus chthonoplastes; e, Spirulina sp.; f, Oscillatoria sp.; g, Pseudoanabaena sp.; h, flexibacterias; i, Chromatium sp.; j, Thiospirillum sp.

Schematic drawing representation of transversal view of a summer microbial mat from the Salada de Chiprana lake showing the different constituent layers of the green (....) and red (-..-) layers. The absortion maxima at 660 and $614 \mathrm{~nm}$ corresponds to chl $\mathrm{a}$, and the $768 \mathrm{~nm}$ maximum corresponds to bchl a.

The letters on the drawing refer to the following: A, diatoms and Cyanobacteria; B, purple sulfur phototrophic bacteria; C, sulfate-reducing bacteria; a, diatoms; b, Gloeocapsa sp.; c, Synechococcus sp.; d, Microcoleus chthonoplastes; e, Spirulina sp.; f, Oscillatoria sp.; g, Pseudoanabaena sp.; h, flexibacteria; i, Chrvmatium sp.; j, Thiospirillum sp. 
bientales. Constituye la única laguna, dentro del contexto de Europa occidental, de aguas hipersalinas, permanentes, profundas y poco fluctuantes.

La presencia de una capa más salina en el fondo permite el establecimiento, en las cubetas de mayor profundidad, de una estratificación casi permanente, algo que es común en muchos lagos kársticos y lagunas costeras de nuestro país pero que no es posible encontrar en otras lagunas esteparias del interior, generalmente someras y temporales.

Por su carácter extremo, la laguna presenta una baja diversidad biológica, constituyendo un medio adecuado para el desarrollo de todo un mundo procariótico. Así, encontramos comunidades microbianas muy particulares, cuyo desarrollo está hoy día restringido a hábitats muy determinados: bacterias fotosintéticas del azufre y tapetes microbianos.

En España se han realizado bastantes estudios sobre las bacterias fototróficas del azufre en lagos kársticos y ambientes hiperhalinos de salinas costeras. Un resumen general de los mismos ha sido publicado por GuERRERo et al. (1987). Sin embargo, no hay apenas datos referentes a este tipo de organismos en lagunas del interior.

Por otra parte, las referencias relativas a la presencia de tapetes microbianos se centran únicamente en salinas costeras en explotación, en concreto las salinas de Santa Pola (Thomas, 1984) y una cita descriptiva de su existencia en lagunas salinas de la Depresión del Ebro (Pueyo, 1978179).

Dentro de las lagunas kársticas estudiadas es frecuente la presencia de capas superpuestas de bacterias fototróficas rojas y verdes del azufre (Cisó, Negre I, Estanya, Banyoles III, Vilar, laguna de la Cruz), estas últimas pertenecientes a las especies Chlorobium limicola y Chlorobium phaeobacteroides. Menos común es la existencia de un único tipo de bacterias fotosintéticas, así, Coromines, Montcortes y lagunilla del Tejo presentan en la capa anóxica densas poblaciones de Chlorobium limicola, junto a Chlorobium phaeobacteroides en el caso de la laguna de Montcortes. Un caso singular sería la presencia como especie dominante de Pelodictyon clathratiforme en la laguna de la Cruz (Cuenca) (VICENTE et al., 1988).

En la Salada de Chiprana se ha observado, durante prácticamente todo el ciclo en estudio, la presencia de una densa capa de grosor variable de bacterias fotosintéticas verdes de azufre. Los resultados obtenidos indican que la población dominante es Chlorobium vibrioforme, posiblemente con algunas adaptaciones a las condiciones fisicoquímicas del medio.

Las especies Chlorobium phaeovibroides y Chlorobium vibrioforme son típicas de aguas saladas. Así, Chlorobiurn phaeovibroides es la especie dominante en las lagunas costeras españolas estudiadas hasta el momento (Cullera, Remolar, Massona) y Chlorobium vibrioforme está presente en la laguna costera de Santona (Cantábria) (R. DE WITT, comunicación personal). Sin embargo, no se ha descrito ninguna laguna endorreica de carácter hipersalino que presente poblaciones dominantes de bacterias fotosintéticas verdes del azufre, siendo la Salada de Chiprana el primer caso observado en nuestro país con una densa capa de Chlorobium vibrioforme. Su presencia podría estar determinada, junto al carácter hipersalino de las aguas, por la elevada concentración de sulfuro de hidrógeno que se alcanza en la zona anóxica.

La Salada de Chiprana posee unas características físico-químicas que la convierten también en un ambiente idóneo para el desarrollo de tapetes microbianos. De hecho, estas comunidades laminadas están recubriendo una gran parte de los sedimentos de la laguna en zonas de poca pendiente.

A diferencia del resto de las lagunas hipersalinas españolas en las que se forman tapetes más o menos consistentes y que generalmente se deshacen durante los períodos de sequía, los tapetes de la Salada de Chiprana permanecen estables durante todo el ano, presentando una consistencia notable en todas las zonas de la laguna permanentemente cubiertas por sus aguas.

El principal responsable de la estructura del tapete es la cianobacteria filamentosa Microcoleus chthonoplastes. Este microorganismo ha sido descrito como organismo predominante en distintos tipos de tapetes microbianos formados en ambientes hipersalinos. En la Península Ibérica aparece en las comunidades laminadas consistentes en las Salinas de Santa Pola, en las cubetas con un margen de salinidad entre 70 y $140 \mathrm{~g} / \mathrm{l}$. Asimismo se ha descrito en lagos salados y lagunas de Australia, Medio Oriente y México (BAuld, 1981).

Los tapetes constituidos básicamente por Microcoleus presentan una gran coherencia, pudiendo 
atrapar eficazmente las partículas sedimentarias tanto de origen detrítico como de precipitación química. En la superficie de los tapetes maduros se observa con frecuencia la formación de conos (pinnacle mat) en aquellas comunidades que están permanentemente sumergidas, de forma similar a los descritos en estas condiciones en las Salinas de Santa Pola (Thomas, 1984) o en el Solar Lake (KKUMBein et al., 1977; JoRGENSEN et al., 1979). Este crecimiento orientado de la capa de cianobacterias se ha intentado explicar en base al gradiente de factores físico-químicos del medio, fundamentalmente luz y oxigenación.

Por otra parte, las bacterias fotosintéticas rojas del azufre se encuentra, durante la mayor parte del ano, dispersas entre las cianobacterias que constituyen la estructura fundamental del tapete, y solamente, en el período estival, con una mayor intensidad lumínica, constituyen una capa netamente diferenciada por debajo de la capa de cianobacterias. Presumiblemente, estas bacterias fotosintéticas migran hacia la zona fótica del tapete en los períodos de menor insolación, donde, por otra parte, la concentración de oxígeno debe ser muy elevada durante el día, hecho que, como indica Desmarais (1990), cuestionaría el punto de vista convencional sobre su tolerancia al oxígeno.

Quedan aún numerosos aspectos por abordar y/o completar en relación a la dinámica y funcionamiento de la Salada: factores que regulan la distribución y estructura de los tapetes, competencia tapetes-macrófitos acuáticos sumergidos, contribución de estos productores primarios en el balance energético global de la laguna, factores que intervienen en las oscilaciones de la capa anóxica y bacterias fotosintéticas del azufre asociadas, etc.

En definitiva, la Salada de Chiprana, por su carácter extremo y su baja diversidad, presenta grandes ventajas para el desarrollo de múltiples estudios sobre limnología de ambientes extremos en general y de ecología microbiana en particular. Su carácter único justifica sobradamente una protección rigurosa de la que actualmente carece. En este contexto, el principal factor de tensión a que se encuentra sometida la laguna, está relacionado con la entrada de agua dulce que produce una disminución del carácter forzado del ambiente y por lo tanto, de su singularidad ecológica.

\section{AGRADECIMIENTOS}

A los guardas del COMENA por las facilidades que nos han prestado para la realización del trabajo de campo. A los Drs. Guerrero, De Wit y Vicente por los comentarios y apoyo en el desarrollo del trabajo. A F. Moya por la realización de algunos análisis químicos. A A.I. López por el dibujo de los tapetes y a las secciones de Fisiología Vegetal y Biología General de la U.A.M. por la utilización de sus instalaciones.

\section{Bibliografía}

American Public Health Association, 1985. Standard methods for the examination of water and wastc-water (16." ed.). APHA. AWWH. WPCF.

Baltanas, A., C. Montes, P. Martino, 1990. Distribution patterns of ostracods in iberian saline lakes. Influence of ecological factors. Hydrohiologia, 197: 207-220.

Ballarin, I., 1985. Clasificación de las zonas húmedas aragonesas de importancia internacional, nacional o regional en función de las aves acuáticas. Monografías n." 40. ICONA, MAPA.

BAULD, J., 1981. Occurrence of benthic microbial mats in saline lakes. Hydrohiologiu, 81: 87-111.

BERNÁldez, F.G., 1987. Las zonas encharcables españolas. El marco conceptual. En: Bases científicas para la protección de los humedales en España: 9-30. Real Academia de Ciencias de Madrid.

Bernues, M., F. Moya, A.G. Besteiro, C. Montes, 1991 Análisis químicos de aguas dulces y saladas. Depto. Interuniversitario de Ecología. Universidad Autónoma de Madrid.

Braun Blanquet, J. \& O. Bolós , 1957. Les groupements vegetaux du Bassin moyent de l'Ebre ct leur dynamisme. Anal. Estac. Exper. Aula Dei, 5 (1-4): 1-266.

Clayton, R.J., 1966. Spectroscopy of bacteriochlorophylls in vivo and in vitro. Photochem. photobiol., 5: 669-677.

DanTIN, J., 1942a. Distribución y extensión del endorreismo aragonés. Estud. Geogr., 3 (8).

DAnTin, J., 1942b. Localización del endorreismo aragonés. Las Ciencias, 7 (3).

Des Marais, D.J., 1990. Microbial mats and the early evolution of life. Tree, 5 (5): 140-144.

Eugster, H.P., L.A. Hardie, 1978. Saline lakes. In: A. Lernion (ed.) Lakes, chemistry, geology, physics: 237-293. Springer-Verlag. New York.

Friend, P.F., J.P.P. Hirst, G.J. Nichols, 1986. Sandstonc body structure and river process in the Ebro Basin of Aragón, Spain. Cuad. Geología Ibérica, 10: 9-30.

Geitler, L., 1932. Kryptogamen flora von Deutchland, ÖSterreich und der Schweiz: Cyanophyceae von Europa. Akademische Verlagsgesellschaft m.b.H., Leipzig.

Gloe, A., H. Pfenning, H. Brockmann \& W. Trowitzsch, 1975. A new bacteriochlorophyll from brown-colored chorobiaceae. Arch. Microbiol., 102: 103-109. 
Guerrero, R., C. Pedrós-Al.ió, I. Esteve \& J. Mas, 1987. Communities of phototrophic sulfur bacteria in lakes of the Spanish Mediterranean region. Acta Academiue Aboensis, 47 (2): 125-151.

HAKANSON, L., 1981. Manual of lake morphometry. SpringerVerlag, New York.

HAMmER, V.I., 1986. Saline lakes ecosystems of the world. Dr. W. Junk Publ., Boston.

IBÁÑEZ, M.J., 1973. Contribución al estudio del endorrcismo de la Depresión del Ebro: el foco endorreico al W y SW de Alcaniz (Tcrucl). Geographica, 15 (1): 21-32.

IBÁÑEZ, M.J., 1975. El endorreismo del sector central de la Depresión del Ebro. Cuadernos de investigación, 1 (2): 35-48.

Izco, J., F. Fernández, A. Molina, 1984. El orden Tamaricctalia Br. BI. \& Bolós. 1957 y su ampliación con los tarayales hiperhalófilos. Documenis phytosociologiques, 8: 377-392.

JAVOR, B.J., 1989. Microbiology and biogeochemistry of hypersaline environmenis. Brock/Springer. Berlín.

Jorgensen, B.B., M.P. Reusbech, T.H. Blackburn \& N CoHEN, 1979. Diurnal cycle of oxygen and sulfide microgradients and microbial photosynthesis in a cyanobacterial mat scdiment. Appl. Environ. Microbiol., 38: 46-58.

Krumbein, W.E., Y. Cohen \& M. Shilo , 1977. Solar Lakc (Sinai), 4-Stromatolitic cyanobacterial mats. Limnol. Oceanography, 22: 635-656.

Margalef Mir, R., 1981. Distribución de los macrófitos y de las aguas dulces y saladas del E y del NE de España y dependencia de la composición química del medio. Fundación Juan March.

Martino, P., 1988. Limnología de las lagunas salinas españolas. Tesis Doctoral. Univ. Autónoma de Madrid.

Mingarko, F., S. Ordonez, C. López Azcona, M.A. Gar. Cfa DEl Cura, 1981. Sedimentoquímica de las lagunas de los Moncgros y su entorno gcológico. Rol. Geol. Min., 42-43: 171-195.

Montes, C. \& P. Martino, 1987. Las lagunas salinas españolas. En: Seminario sobre bases cientificas para la protección de los humedales en España: 95-145. Real Academia de Ciencias Exactas, Físicas y Naturales de Madrid. Madrid.
POR, F.D., 1980. A classification of hipersaline waters based on trophic criteria. Mur. Biol., 1: 121-131.

PuEYO, J.J., 1978/79. La precipitación evaporítica actual en lagunas saladas. Revista del Instituto de Investigaciones Geológicas. Diputación Provincial. Universidad de Barcelona, Vol. 33: 5-56.

QUIRANTES, J.. 1978. Estudio sedimentológico y estratigráfico del Terciario continental de los Monegros. Instituto Fernando el Católico. Diputación Provincial de Zaragoza.

Reyes Prosper. E., 1915. Las estepas de España y su vegeta ción. Madrid.

Riba, O., J. Villena \& J. Quirantes, 1967. Nota preliminar sobre la sedimentación en paleocanales terciarios de la Zona de Caspe-Chiprana (provincia de Zaragoza). Anal. Edaf. Agrob.. 26 (1-4): 617-634.

Ripka, R.. J. Deruelles. J.B. Waterbury, M. Herdman \& R.Y. STAMIER, 1979. Generic assignments, strain, histories and properties of pure cultures of Cyanobacteria. J. Gen. Microbiol., 111: 1-61.

Stal, L.J., H. van Gemerden \& W.E. Krumbein, 1984. The simultaneous assay of chlorophyll and bacteriochlorophyll in natural microbial communities. J. Microbiol. Methods, 2: 295-306.

STALEY, J.T. (ed.) (1989). Bergey's manual of systematic bacteriology. Vol. 3. Williams \& Wilkins.

ThOMAS, J.C., 1984. Formations benthiques a Cyanobactéries des salins de Santa Pola (Espagne): Composition spécifique, morphologie et caractéristiques biologiques des principaux peuplements. Rev. Inv. Geol., 38139: 139-158.

VAN Gemerden, H. \& H.H. BeEfTinK, 1985. Ecology of phototrophic bacteria. Appcndix: Cultivation methods. In: The photoirophic bacteria: Anaerobic life in the light. S.G. Ormerod (ed.). Cap. 8. Blackwell. London.

Vicente, E. \& M.R. Miracle, 1988. Physicochemical and microbial stratification in a meromictic karstic lake of Spain. Verh. Internat. Verein. Limnol., 23: 522-529.

Wetzel, R.G., 1983. Limonology. 2nd ed., Saunder.

Williams, W.D., 1986. Limnology, the study of inland waters: a comment on perception of studies of salt lakes, past and present. En: P. de Deckkcr \& W.D. Williams (ed.) Limnology in Australia: 471-496. Dr. W. Junk Publishers, Boston. 